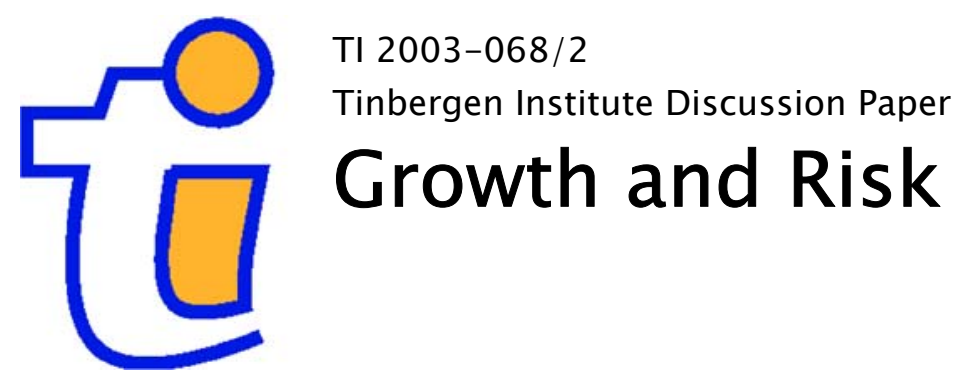

Chris Elbers

Jan Willem Gunning* Bill Kinsey

Faculty of Economics, Vrije Universiteit Amsterdam.

* Tinbergen Institute. 


\section{Tinbergen Institute}

The Tinbergen Institute is the institute for economic research of the Erasmus Universiteit Rotterdam, Universiteit van Amsterdam, and Vrije Universiteit Amsterdam.

Tinbergen Institute Amsterdam

Roetersstraat 31

1018 WB Amsterdam

The Netherlands

Tel.: $\quad+31(0) 205513500$

Fax: $\quad+31(0) 205513555$

Tinbergen Institute Rotterdam

Burg. Oudlaan 50

3062 PA Rotterdam

The Netherlands

Tel.: $\quad+31(0) 104088900$

Fax: $\quad+31(0) 104089031$

Most TI discussion papers can be downloaded at http:/ /www.tinbergen.nl. 


\title{
Growth and Risk:
}

\section{Methodology and Micro Evidence}

\author{
Chris Elbers, Jan Willem Gunning and Bill Kinsey ${ }^{1}$
}

Revised September 2006

\footnotetext{
${ }^{1}$ All three authors are with the Department of Economics, Free University, Amsterdam. Their email addresses are celbers@feweb.vu.nl, jgunning@feweb.vu.nl and bkinsey@feweb.vu.nl. For very helpful comments we are grateful to the Editor and three anonymous referees of the Review and to Hans Binswanger, Stefan Dercon, Ravi Kanbur, Peter Lanjouw, Ethan Ligon, Martin Ravallion, Elisabeth Sadoulet, T.N. Srinivasan, Erik Thorbecke, Steve Younger and seminar participants at Amsterdam, Berkeley, Clermont-Ferrand, Cornell, Harvard, Leuven, Oxford, Rotterdam and the World Bank. We are grateful to Trudy Owens who provided us with the aggregate crop income data which she constructed. A supplemental appendix to this article is available at http://wber.oxfordjournals.org/.
} 


\begin{abstract}
How exposure to risk affects economic growth is a key issue in development. In this paper we quantify both the ex ante and ex post effects of risk, using a long-running panel data set for rural households in Zimbabwe. The paper proposes a simulation-based econometric methodology to estimate the structural form of a micro model of household investment decisions under risk. The key finding is that (in this particular setting) risk substantially reduces growth: the mean capital stock in the sample is (in expectation) $46 \%$ lower than in the absence of risk. About two-thirds of the impact of risk is due to the ex ante effect (i.e. the behavioral response to risk) which is usually not taken into account in policy design. These results suggest that policy interventions which reduce exposure to shocks or help households in risk management could well be much more effective than is commonly thought.
\end{abstract}

JEL Codes: D10, D91, C51, O12

Keywords: risk and investment; estimation by simulation; empirical Ramsey model 


\section{Introduction}

Growth and risk are central issues in development. While the two phenomena are usually studied in isolation it has often been suggested that they are closely linked. For example, Collier and Gunning (1999) argue on the basis of micro-economic evidence that the responses of agents to risk are an important part of the explanation for Africa's poor growth performance. Risk management involves changes in the choice of activities: households may choose low-risk activities or portfolio's of activities which are well diversified. Diversification is, of course, costly: the household foregoes the gains from specialisation. In itself this is a level effect which does not necessarily affect growth. However, level effects easily translate into growth rate effects, e.g. when there are indivisibilities in investment and imperfections in credit markets. This conjunction is typical for many rural areas in Africa.

In addition to risk management through activity choice households use various risk coping strategies. In the absence of well-functioning credit and insurance markets self-insurance (saving and dissaving in response to income shocks to smooth consumption) and informal social security institutions are used as substitutes. Consumption smoothing typically involves changes in food stores, livestock or both. These assets are themselves subject to substantial risks (livestock illnesses, theft, vermin, spoilage) and this makes consumption smoothing less effective as a risk coping strategy.

There is growing evidence on the costs of such risk management and coping mechanisms: they lower income, perpetuate poverty and cause the effects of shocks to persist over long periods (e.g. Rosenzweig and Binswanger, 1993, Morduch, 1999, Dercon, 2003 and 2004, Jalan and Ravallion, 2005). The significance of growth-reducing responses to risk is now widely recognised, but neither the theoretical nor the empirical literature provides much guidance for quantifying the effect of risk on growth.

Much of growth theory is, of course, deterministic so that the issue cannot be addressed. 
Recently there has been a revival of interest in growth under uncertainty (e.g. Binder and Pesaran, 1999, de Hek, 1999; after early contributions such as Levhari and Srinivasan, 1969) but these contributions typically treat rather special cases. For example, risk has no ex post effect in the Levhari-Srinivasan model and no ex ante effect in the Binder-Pesaran paper. ${ }^{1}$

In the empirical literature there also is a growing interest in the effect of risk on growth, both at the macro and the micro level (examples are Ramey and Ramey, 1995, Guillaumont and Chauvet, 2001, Jalan and Ravallion, 2001). Most of these studies use a reduced form specification for the income generating process. There are a few examples of structural models, e.g. Rosenzweig and Wolpin (1993) who analysed optimal accumulation under risk in Indian villages. They concluded that introducing actuarially fair insurance in these villages would not raise welfare: farmers are already adequately protected through informal insurance. Formal insurance therefore offers no benefits and (in their model) does not lower the cost of risk coping either. ${ }^{2}$ As a result, Rosenzweig and Wolpin find no effect on investment when risk is reduced.

In this paper we estimate an intertemporal optimisation model for a farm household, using a unique long-running panel dataset for rural households in Zimbabwe. These households make little use of financial assets and of informal insurance and their investment largely takes the form of building up their own livestock herd. In analysing their behavior we focus on consumption smoothing as the key risk-coping strategy available to them. In this respect our model is similar to that of Deaton (1991). However, in Deaton's model households have no

\footnotetext{
${ }^{1}$ Similarly, Lucas $(1987,2003)$ in his famous back-of-envelope calculation of the welfare effect of eliminating business cycles implicitly assumes that risk has no ex ante effect.

${ }^{2}$ Profits are net of the implicit premium paid for informal insurance but this premium is not known. Hence if farmers were to switch from informal to formal insurance the constant term in the profits function is not adjusted: farmers would implicitly continue to pay for informal insurance (Rosenzweig and Wolpin, 1993, n. 12).
} 
incentive to save in the absence of risk ${ }^{3}$ and they have access to a safe asset. ${ }^{4}$ The model we use to describe the Zimbabwean farmers differs in both respects. First, it exhibits conditional convergence in the absence of risk. Households start very poor, with asset holdings far below the steady state level. As a result they have an incentive to accumulate capital (livestock). This process of growth ${ }^{5}$ gives us a benchmark for addressing the growth and risk question: we can compare accumulation under risk with this no-risk counterfactual. Secondly, households are exposed to shocks which affect both livestock itself and the income from agriculture where livestock is used as an input. Hence these farmers have no access to a safe asset.

Since we explicitly model the costs and benefits of consumption smoothing we can assess the impact of actuarially fair insurance or, equivalently, the effect of risk on growth. Whether that effect is strong or weak, positive or negative is an empirical matter: the model can in principle generate widely different results. In particular whether risk increases or reduces households' propensity to accumulate assets is not implied by our specification. It depends on the nature of risk (notably the relative importance of income and asset shocks) and on how risk averse households are. Rather than resolving these issues a priori we leave them to the estimation phase. When we use the estimated micro growth model to assess the effect of risk on growth we in fact find a very strong negative effect. Under risk the expected value of the capital stock at the end of a 50-year simulation period is $46 \%$ lower than it would have been in the counterfactual riskless case.

Risk not only reduces capital accumulation and hence growth, it also has a negative effect on household welfare. Our results suggest that policy measures that reduce the risk exposure

\footnotetext{
${ }^{3}$ Dercon (1996) extends Deaton's model by making agricultural income depend on the allocation of labor between two crops, one risky, the other risk-free. In this model removing risk leads to full specialisation but the effect on growth cannot be analysed: as in Deaton's model there is no incentive for accumulation in the absence of risk.

${ }^{4}$ Dercon (2005) stresses that models of consumption smoothing (e.g. Deaton, 1991) often assume that agents have access to a safe asset. This overstates the effectiveness of consumption smoothing as a risk coping strategy.

${ }^{5}$ Since the model has a steady state growth should be understood as transitional dynamics.
} 
of these households or that would offer more efficient risk coping (e.g. through insurance) would have powerful effects, not only on growth but also on household welfare.

The structure of the paper is as follows. The next section sets out a decomposition of the effect of risk into ex ante and ex post components. In section 3 we introduce our model. Section 4 describes the survey data. Estimation is discussed in section 5 and the simulation results in section 6 . Section 7 concludes.

\section{Ex Ante and Ex Post Effects of Risk}

A household's economic decisions (e.g. on savings) are affected by risk in two ways: through the household's experience of shocks and through its perception of the distribution of shocks it faces. It is useful to formalise this distinction. Suppose household investment decisions can be summarised as:

$$
k_{t+1}=\varphi\left(k_{t}, s_{t} ; \sigma\right)
$$

where $k$ denotes the household's capital stock, $s$ a shock (with expected value $E s=1$ ) and $\sigma$ a parameter characterising the distribution from which $s$ is drawn. At this stage the definition of $\sigma$ is irrelevant but we will interpret an increase of $\sigma$ as an increase in risk and will describe the riskless case as $\sigma=0$. In general risk affects $k_{t+1}$ (and thereby growth in the sense of transitional dynamics) not just through $s$, but also through $\sigma$. Changes in $\sigma$ will (in general) change the household's behaviour: the household will choose a different value of $k_{t+1}$ for the same values of $k_{t}$ and the current shock $s_{t}$. We call this the ex ante effect of risk. An example would be the effect of the possibility that a civil war will break out on investment behavior. The household has not yet been exposed to a shock but it knows that peace is precarious. Its assessment of the likelihood of violent conflict will have a powerful effect on its investment decisions. Hence the ex ante effect results from the household's 
view of the world: two households which differ in their perception of the risks they face but which are identical in all other respects will in general take different investment decisions. By contrast the ex post effect measures the impact of the shocks themselves. The effect of risk can be decomposed in an ex ante and ex post component as follows.

Applying (1) repeatedly we can write

$$
k_{t+T}=g\left(k_{t} ; s_{t}, s_{t+1, . .} s_{t+T-1} ; \sigma\right)
$$

for some suitably defined function $g()$. Taking expectations

$$
\begin{aligned}
E_{t} k_{t+T} & =E_{t} g\left(k_{t} ; s_{t}, s_{t+1, . .} s_{t+T-1} ; \sigma\right) \\
& =g\left(k_{t} ; 1,1, . ., 1 ; \sigma\right)-\left[g\left(k_{t} ; 1,1, . ., 1 ; \sigma\right)-E_{t} g\left(k_{t} ; s_{t}, s_{t+1, . .} s_{t+T-1} ; \sigma\right)\right] \\
& =g\left(k_{t} ; 1,1, . ., 1 ; \sigma\right)-[\text { ex post effect }] \\
& =g\left(k_{t} ; 1,1, . ., 1 ; 0\right)-\left[g\left(k_{t} ; 1,1, . ., 1 ; 0\right)-g\left(k_{t} ; 1,1, . ., 1 ; \sigma\right)\right]-[\text { ex post effect }] \\
& =g\left(k_{t} ; 1,1, . ., 1 ; 0\right)-[\text { ex ante effect }]-[\text { ex post effect }]
\end{aligned}
$$

hence

$$
g\left(k_{t} ; 1,1, . ., 1 ; 0\right)-E_{t} k_{t+T}=[\text { ex ante effect }]+[\text { ex post effect }] .
$$

Here $g\left(k_{t} ; 1,1, . ., 1 ; 0\right)$ is the value of $k_{t+T}$ which the household would attain in a risk-free world (with $\sigma=0) ; g\left(k_{t} ; 1,1, . ., 1 ; \sigma\right)$ is the hypothetical value reached if the household expects shocks drawn from a distribution with positive $\sigma$, but in fact experiences no shocks ( $s=1$ in all periods). Note from (2) that the two effects are defined in such a way that a positive value implies that growth is reduced. In section 6 we will apply the decomposition (2) in our analysis of risk in Zimbabwe.

That shocks can make the path of $k$ volatile is obvious; but that risk affects the expectation $E k$ is not. Indeed, there is no presumption in theory about the sign (let alone the 
size) of the ex ante and ex post effects. The effect of risk on growth is therefore an empirical issue.

Usually in empirical research equation (1) is estimated by regressing $k_{t+T}$ (or some other proxy for growth) on various controls (country characteristics in macro growth regressions, household characteristics in micro studies), measures of $s$, and, possibly, measures of $\sigma$. Two cases can arise, depending on data availability. If $\sigma$ does not vary in the sample (e.g. because all households face the same rainfall risk, $\sigma=\bar{\sigma}$ ) then (without further identifying restrictions) the effect of changes in $\sigma$ (the ex ante effect) can obviously not be identified and only $k_{t+1}=\varphi\left(k_{t}, s_{t} ; \bar{\sigma}\right)$ can be estimated. The estimated function can then be used to measure the ex post effect (by imposing $s_{t}=1$ ) but the total effect of risk cannot be identified. On the other hand, when there is variation in risk (for example, in cross-country growth regressions if country-specific measures of climatic risk are available) then both the ex ante and ex post effects can in principle be identified. ${ }^{6}$

In our sample all households face the same risk so there is no variation in $\sigma$. A reduced form estimation of equation (1) would therefore at best produce an estimate of the ex post effect. In order to identify the ex ante effect as well we estimate the model in its structural form rather than as a reduced form. The assumption that household behavior is generated by intertemporal optimisation makes it possible to identify the effect of changes in $\sigma$.

It should be noted that we define the ex post effect of risk in terms of changes in the expected outcome $E k_{t+T}$ : we are not concerned with the effect of a particular realisation $s_{t}$ (or series of shocks $s_{t}, s_{t+1}, .$. ). There exists a literature which does investigate the impact of such realisations on outcomes $k_{t+T}$ (rather than on its expected value). ${ }^{7}$ For example, Dercon and Krishnan (2000) study the effect of illnesses on household consumption and

\footnotetext{
${ }^{6}$ For example, Dehn (2000) includes both actual trade shocks and a country-specific measure of the distribution of trade shocks in a growth regression. Ramey and Ramey (1995) estimate a cross-country growth regression in which the standard deviation of the error term is country-specific and affects growth.

${ }^{7}$ Such studies work in the tradition of Knightian uncertainty whereas our approach assumes that shocks are frequent and that agents know their distribution.
} 
Alderman et al. (2004) investigate the persistent effects of a drought in Zimbabwe on the health of children. Similarly, the trade shocks literature (e.g. Collier and Gunning, 1999a) studies the impact (and its persistence) of changes in the terms of trade. By contrast in this paper we focus on the impact of changes in risk (in the sense of mean preserving changes in the distributions of shocks) rather than on the impact of particular shocks.

\section{The Model}

We assume that there is a single good, used for consumption, as a store of value and as a productive asset. Agents maximise expected utility over an infinite horizon. ${ }^{8}$ Each household solves:

$$
\max _{\left\{c_{t}, k_{t+1}\right\}} E_{0} \sum_{t=0}^{\infty} \beta^{t} u\left(c_{t}\right)
$$

subject to

$$
\begin{aligned}
c_{t} & =s_{1 t} \lambda a f\left(k_{t}\right)+s_{2 t}(1-\delta) k_{t}-k_{t+1} \\
\text { for } t & =0,1,2, . . \text { and } k_{0}, s_{10}, s_{20} \text { given }
\end{aligned}
$$

where $c$ denotes consumption, $k$ the capital stock, $a$ household-specific total factor productivity, $u$ the instantaneous utility function, $f$ the production function, $\beta$ a discount factor, $\delta$ the depreciation rate, $\lambda$ the relative price of output (in terms of the asset) and $t$ time. ${ }^{9}$ We assume strict concavity of $u$ and $f$ and $0<\beta<1$. Note that $\beta$ and $\delta$ are constant.

The household faces both income $\left(s_{1}\right)$ and asset $\left(s_{2}\right)$ shocks. When the household decides on $c_{t}$ and $k_{t+1}$ both $k_{t}$ and the realizations $\left(s_{1 t}, s_{2 t}\right)$ are known. Future shocks are, of

\footnotetext{
${ }^{8}$ There are well-known critiques of expected utility. Recursive utility (Epstein and Zin, 1991) is an attractive alternative specification and our recursive modelling and estimation strategy (based on the Bellman equation) lends itself to this alternative. In future work we intend to investigate whether the results on growth and risk are sensitive to changes from the expected utility framework.

${ }^{9}$ Total factor productivity is time invariant from the household's point of view. In fact it changes, e.g. with household size. Such changes are modelled as part of the shocks to which the household is exposed.
} 
course, unknown but the household knows the distributions of these shocks. (Note that this assumption of rational expectations excludes learning processes whereby the household adjusts its estimates of the distribution of shocks.)

In our application we allow for two types of heterogeneity: households differ in their initial capital stock $(k)$ and in productivity $(a)$.

Some of the limitations of the stochastic Ramsey model (3) should be noted. First, each household is modelled as a Robinson Crusoe economy and this is clearly restrictive. In particular, households are not linked through credit transactions or risk pooling. Descriptive evidence suggests that there are indeed few credit transactions in this sample but informal risk pooling arrangements do exist. Modelling such existing arrangements is a challenge for future research. In the present paper we proceed as if there are no risk pooling arrangements so that consumption smoothing is the only risk coping strategy available to households. This is clearly restrictive and it might be objected that by assuming away risk-pooling we necessarily overstate the effect of risk on growth. We consider this point in section 5 .

Secondly, in the model the capital stock used in production is the only asset available to the household. For our Zimbabwe application this is reasonable: the resettlement programme ruled out diversification into non-agricultural activities and these households have very few assets other than livestock. Obviously, it is desirable to allow for multiple assets so as to be able to model multiple crops or financial assets. However, allowing for multiple assets in agricultural production greatly increases the computational burden of estimating and simulating the model. ${ }^{10}$ Introducing financial assets is much less problematic, provided the agricultural asset (livestock) is tradable. The reason is that under this condition the policy function continues to have a single argument, wealth at hand.

Thirdly, we treat the relative price $\lambda$ (for which we have no observations) as constant

\footnotetext{
${ }^{10}$ Rosenzweig and Wolpin (1993) in a somewhat similar model reduce this burden by imposing indivisibilities (e.g. by allowing for only three levels of cattle ownership: 0, 1 and 2). This seems very restrictive.
} 
over time. This implies that price-related risk is captured in $s_{1}$.

It is important to note that the Ramsey specification does not imply that the ex ante effect is either positive or negative. A well-known result (e.g. Newbery and Stiglitz, 1981, p. 396) is that in a two-period model with a safe asset strict convexity (concavity) of the marginal utility function implies a positive (negative) effect of risk on investment. ${ }^{11}$ However, the sign of the effect does not only depend on the utility function but also on the nature of shocks. This may be illustrated by considering a two-period version of our model:

$$
\max _{k_{2}} u\left(c_{1}\right)+\beta E u\left(c_{2}\right)=u\left(s_{11} a f\left(k_{1}\right)+s_{21}(1-\delta) k_{1}-k_{2}\right)+\beta E u\left(s_{12} a f\left(k_{2}\right)+s_{22}(1-\delta) k_{2}\right)
$$

with $k_{1}, s_{11}, s_{21}$ given. Assume unitary relative risk aversion: $u(c)=\ln c$. If risk only affects income (i.e. $s_{2 t} \equiv 1$ ) then the first-order condition is

$$
u^{\prime}\left(c_{1)}\right)=\beta E \frac{s_{12} a f^{\prime}\left(k_{2}\right)+(1-\delta)}{s_{12} a f\left(k_{2}\right)+(1-\delta) k_{2}} .
$$

The concavity of $f$ implies that the expression after the expectation sign is strictly convex in $s_{12}$. Hence an increase in risk (i.e. a mean preserving spread applied to the distribution of $s_{12}$ ) raises the right hand side of the condition. Equilibrium is restored through an increase in the optimal value of $k_{2}$. It follows that the effect of risk on investment is positive in this case. Conversely, if risk applies only to assets (so that $s_{1 t} \equiv 1$ ) then an increase in risk

\footnotetext{
${ }^{11}$ Consider the model
}

$$
\max _{k_{2}} u\left(c_{1}\right)+\beta E u\left(c_{2}\right)=u\left(s_{11} y-k_{2}\right)+\beta E u\left[s_{12} y+(1+r) k\right]
$$

where $s_{11}$ is known, $y$ is the mean of non-asset income and $r$ the return on the safe asset $k$. The first-order condition is

$$
u^{\prime}\left(c_{1}\right)=(1+r) \beta E u^{\prime}\left(c_{2}\right) .
$$

Clearly, if $u^{\prime}\left(c_{2}\right)$ is strictly convex in $s_{12}$ then an increase in risk would increase the right-hand side of the condition and an increase in $k_{2}$ would be required to maintain equilibrium. Hence in this model the effect of risk on savings is positive for a convex marginal utility function. 
reduces the optimal value of $k_{2} \cdot{ }^{12}$ (In a multiperiod model asset shocks are more important in the sense that their effect is permanent whereas income shocks have no persistence. This makes a negative effect of risk on growth more likely.) This example indicates that the relative importance of the two types of shocks, an empirical matter, is another determinant of the sign of the effect of risk on growth in our model. ${ }^{13}$

In the Zimbabwe study the effect of risk on growth is dominated by the ex ante effect. Again, this is not an implication of the Ramsey model. For example, in the special case with $\log$ utility, $f(k)=k^{\alpha}$ and $\delta=1$ there is no ex ante effect, while there is an ex post effect.

\section{Data}

In the early 1980s the government of Zimbabwe undertook a land reform programme which involved resettlement of peasant farmers and landless labourers on land formerly owned by commercial white farmers. ${ }^{14}$ To be eligible for resettlement household heads had to be married (or widowed), not in formal employment, and not younger than 18 years or older than 55. They were randomly assigned to resettlement schemes and had to renounce any claims to land elsewhere. Initial landholdings were identical: each settler was assigned 5 ha. of arable land. Resettled households could engage only in farming, an important restriction since this ruled out risk-coping through diversification into non-agricultural actvities. Since all households received the same area of arable land and land cannot be sold (and there is virtually no land rental) households are basically identical in terms of landholding. However, after twenty years of heterogeneity in terms of demographic growth they differ markedly in land/man ratios. They also differ in terms of total factor productivity: there are very large

\footnotetext{
${ }^{12}$ These results follow from application of Jensen's inequality to the first-order condition.

${ }^{13}$ This is related to Dercon's (2005, pp. 14-15 and Appendix) simulation results showing that asset risk greatly reduces the effectiveness of consumption smoothing compared to the case modelled by Deaton (1992, ch.6) where risk affects income but households have access to a riskless asset.

${ }^{14}$ This section is based on Gunning et al. (2000) and Hoogeveen (2001).
} 
yield differences, controlling for farm inputs. Some are simply much better farmers than others. There are also very large differences in livestock ownership. Livestock is the most important asset in this rural economy.

The key risk in these village economies is rainfall. This risk is, of course, highly covariant, limiting the scope for local risk pooling. While there is some informal insurance in the survey villages there is no formal credit or insurance and the dominant risk coping strategy is consumption smoothing through the use of livestock. Herds are built up after a good harvest while in bad times cattle is used for own consumption, either directly or by selling cattle to finance the purchase of maize, the staple crop. ${ }^{15}$

In 1983/84 Bill Kinsey surveyed a sample of about 400 of the resettled households. The sampling frame consisted of all resettlement schemes established in the first two years of the programme. The sample was restricted to the three most important natural regions (NRs) or agro-climatic zones. In Zimbabwe these are designated as NR II ("moderately high agricultural potential"), III ("moderate potential") and IV ("restricted potential"). One scheme was selected randomly for each zone: Mupfurudzi in Mashonaland Central (north of the capital Harare) for NR II, Sengezi in Mashonaland East (south east of Harare) for NR III and Mutanda in Manicaland (also south east of Harare) in NR IV. Stratified sampling was then used to select 20 villages within these schemes, and for each selected village in two of the areas a complete census was attempted, while in the third area 10 households were randomly selected from each village.

The households were first interviewed in 1983/84, shortly after their resettlement and reinterviewed first in 1987 and then annually since 1992. They have now been followed for two decades, making this the longest running panel dataset in Africa. ${ }^{16}$ The panel data span a

\footnotetext{
${ }^{15}$ For the purpose of this paper this is very fortunate: while rural households in Africa typically engage in a range of non-agricultural activities the resettled households were restricted to farming in the period considered.

${ }^{16}$ In this paper we use the NR II data only. There is remarkably little sample attrition. Approximately $90 \%$ of households interviewed in 1983/84 were re-interviewed in 1997. There is no systematic pattern to the few
} 
period in which these households' assets and incomes grew very rapidly, in spite of exposure to massive shocks, including a severe drought. The questionnaire includes questions on crop production, sales, labour hiring, credit, food storage and anthropometrics and detailed information on livestock ownership. ${ }^{17}$ There are no data on household consumption. Initially the scope of the survey was more limited. The questions were partly retrospective; for example, the first survey round in 1983/84 asked about initial livestock holdings, at the time of resettlement. We have observations on $k_{t}$ for five points in time: at the time of resettlement, 1992, 1993, 1996 and $2000 .^{18}$ We have information on crop income for only two points in time: 1993 and 1996. We measure covariant risk by the log of rainfall for which location-specific timeseries are available.

The empirical study of economic growth is riddled by measurement error problems (Bliss, 1999; Carroll, 2001). We expect measurement errors to be less serious in our application. First, by using a micro data set we use a single method of measurement unlike growth regressions which have to rely on data collected by different institutions. Secondly, we can base our estimations on asset (livestock) rather than income data. While income and expenditure data are notoriously noisy the importance of cattle in most African societies suggests that the most important component of livestock is measured fairly accurately.

households that dropped out. Some were inadvertently dropped during the re-surveys, a few disintegrated (such as those where all adults died) and a small number were evicted by government officials. It should be noted that what is tracked is the land assigned to the original settlers, not the household itself: the household is retained even if its composition changes. The most important such change is the death of the household head, but even this is rare (Hoogeveen, 2001, pp. 45-46).

${ }^{17}$ The survey collected data on various types of livestock (oxen, heifers, goats, etc.). These were aggregated using constant market prices following Hoogeveen (2001).

${ }^{18}$ The households in the sample accumulated cattle very rapidly between resettlement and 1992 (Gunning et al., 2000). The absence of data for the intervening years is an unfortunate limitation of this dataset. In the estimation the time of resettlement was set at 1980 for all households. 


\section{Estimation}

The estimation proceeds in two steps. ${ }^{19}$ We first estimate the production function and a relation determining total factor productivity. ${ }^{20}$ We assume a CES production function in capital and labour with parameters $\rho$ and $\psi$ :

$$
f(k ; n)=n\left(1+\psi\left((k / n)^{-\rho}-1\right)\right)^{-1 / \rho}
$$

where $n$ is householdsize. We assume that total factor productivity is a function of household's size and the highest educational attainment of its adult members at the time of resettlement $(e)$ :

$$
a=\alpha_{0}+\alpha_{1} n+\alpha_{2} e
$$

Denote crop income by $y=a f$. We estimate the function af using data for two years, 1993 and $1996 .^{21}$ Treating productivity $a$ as a household fixed effect we estimate the parameters $\psi$ and $\rho$ in (4) by non-linear regression of $y_{96} / y_{93}$ on $f\left(k_{96}\right) / f\left(k_{93}\right)$. The parameters of (5) are then estimated by regressing $\ln \left(y_{t} / f\left(k_{t}, n_{t} ; \hat{\psi}, \hat{\rho}\right)\right)$ on household size and education, allowing for household random effects. The results are shown in Table $1 .{ }^{22}$

Note that productivity is decreasing in household size and increasing in education; however, these effects are not significant. The estimated value of $\rho$ implies a substitution elasticity (equal to $1 /(1+\rho)$ ) of about 2 . It does not differ significantly from 0 , i.e. from the

\footnotetext{
${ }^{19} \mathrm{~A}$ detailed description of our estimation procedures is given in Elbers and Gunning (2003), available at http://wber.oxfordjournals.org/. This includes tests of robustness and regression diagnostics.

${ }^{20}$ In principle all parameters could be estimated simulataneously. However, production data are available for only two years in the Zimbabwe data set. This is why we proceed in two steps.

${ }^{21}$ The usual objection to direct estimation of the production function: that outputs and inputs are determined simultaneously does not carry much force in the present situation. Since households are exposed to shocks the optimal use of inputs is continually disturbed.

${ }^{22}$ The results are virtually the same if no random effect is included: in that case the estimates for $\psi$ and $\rho$ are 0.5340 and -0.4713 respectively. Similarly, specifying $a$ as a loglinear function of education and household size does not lead to substantially different results.

${ }^{23}$ The standard errors of $\alpha_{0}, \alpha_{1}$ and $\alpha_{2}$ are based on simulation to take into account the sampling variance of $\widehat{\psi}$ and $\widehat{\rho}$.
} 


\begin{tabular}{lrrl} 
& $\begin{array}{r}\text { Point } \\
\text { Parameter }\end{array}$ & $\begin{array}{r}\text { Standard } \\
\text { Estimate }\end{array}$ & \\
\hline Error $_{0}{ }^{23}$ & \\
$\alpha_{1}$ & 1429 & 347 & \\
$\alpha_{2}$ & -9.842 & 19.9 & household size \\
$\psi$ & 54.038 & 34.3 & education \\
$\rho$ & 0.5315 & .153 & capital share \\
& -0.5394 & 1.01 &
\end{tabular}

Table 1: Production Function Estimates

Cobb-Douglas case with unitary substitution elasticity. We have decided to retain the point estimate rather than imposing the Cobb-Douglas value $(\rho=0)$.

Given the parameters of the function af we now estimate the remaining parameters. We extend the model of equation (3) to allow for Hicks-neutral technical progress at a constant rate $\tau$. Define $\widetilde{c}_{t}=c_{t}(1+\tau)^{-t}$ and $\widetilde{a}=\lambda a(1+\tau)^{-t}$. (Recall that $\lambda$ denotes the fixed relative price of ouput in terms of the asset.) The revised model becomes:

$$
\max _{\left\{c_{t}, k_{t+1}\right\}} E_{0} \sum_{t=0}^{\infty}\left(\beta(1+\tau)^{\gamma}\right)^{t} \widetilde{c}_{t}^{\gamma}
$$

subject to

$$
\begin{aligned}
(1+\tau) k_{t+1} & =s_{1 t} \widetilde{a} f\left(k_{t}\right)+s_{2 t}(1-\delta) k_{t}-\widetilde{c}_{t} \\
\text { for } t & =0,1,2, . . \text { and } k_{0}, s_{10}, s_{20} \text { given }
\end{aligned}
$$

We assume that the utility function (common to all households) is of the CRRA-type, $u(c)=c^{\gamma}$ for $\gamma<1$ and $u(c)=\ln c$ for $\gamma=0$ (unitary relative risk aversion). Discount rates are identical across households.

We allow for both idiosyncratic and covariant risk:

$$
\ln s_{i t}=\pi r_{t}+\varepsilon_{i t} \text { for } i=1,2
$$


where $r$ measures covariant risk, $\varepsilon_{i}$ idiosyncratic risk and $\pi$ is a parameter. We assume that risks are independent over time but we allow for correlation between $\varepsilon_{1 t}$ and $\varepsilon_{2 t}$. In our application $\varepsilon_{1}, \varepsilon_{2}$ are jointly normally distributed (with mean 0) and independent of $r$ which is also normal.

We have rainfall data for the covariant risk $r$. (We tried to estimate separate elasticities $\pi_{1}$ and $\pi_{2}$. However, this suggested a high degree of correlation. We therefore impose $\pi_{1}=\pi_{2}=\pi$.) We have no data for the idiosyncratic shocks; this is left to the estimation procedure. Demographic change (birth, death and disability) in the context of Zimbabwean farmers is largely unplanned; we therefore incorporate it in the idiosyncratic part of the shocks. We assume rational expectations: households know the distributions of the shocks.

There now are nine parameters to estimate: $\gamma$, the parameter of the utility function; $\beta$, the discount factor; $\lambda$, the relative price; $\delta$, the rate of depreciation; $\pi$ the rainfall elasticity; $\left(\sigma_{1}^{2}, \sigma_{12}, \sigma_{2}^{2}\right)$ the parameters of the distribution of the idiosyncratic shocks; and $\tau$, the rate of technical progress. (Clearly only the product $a \lambda$ can be estimated. We identify $\lambda$ by setting the average value of $a$ equal to 5.$)$

We estimate these parameters by Simulated Pseudo Maximum-Likelihood. ${ }^{24}$ We first choose a set of parameter values, a vector $\theta$. Given these parameters, we solve the optimisation problem for each household $h$. This gives us a household-specific policy function $\varphi(w)$ which gives optimal investment as a function of wealth on hand $(w)$ as determined by the capital stock and shocks in the current period: $k_{t+1}=\varphi\left(w_{t}\right)$ where $w_{t}=s_{1 t} \widetilde{a} f(k)+s_{2 t}(1-\delta) k_{t}$. In the Appendix we describe how this function can be approximated.

This policy function can now be used in simulation experiments. Given an initial value $k_{t}$ and randomly generated shocks $s_{1 t}$ and $s_{2 t}$ the optimal value of $k_{t+1}$ can be calculated. In this way we generate paths of accumulation over the time intervals between dates for which we have observations: 1980, 1992, 1993, 1996, and 2000. Conditional on rainfall (the

\footnotetext{
${ }^{24}$ See e.g. Gouriéroux and Montfort (1996), section 3.2.
} 
shock component common to households) the changes in capital stocks between observation dates are statistically independent across households and time intervals. We generate a large number of paths by drawing new values for the household idiosyncratic shocks $s_{1 t}$ and $s_{2 t}$.

We then calculate interval-specific means and variances. Since we have a ragged panel we need to make an assumption about the distribution of $k$; we assume that the distribution of changes in $k$ is lognormal. This is sufficient to calculate the likelihood $\mathcal{L}(\theta)$ of the observations for the given parameter vector $\theta$. We then change the parameter vector, using hill-climbing to maximize the likelihood with respect to the parameters. In this way we obtain pseudo maximum likelihood estimates of the nine parameters.

The results of this procedure are reported in Table 2. The standard errors are based on simulations to take into account the sampling variance of the production function parameters. $^{25}$

\footnotetext{
${ }^{25}$ Cf. Murphy and Topel (1985).
} 


\begin{tabular}{|c|c|c|c|}
\hline Parameter & $\begin{array}{l}\text { Point } \\
\text { Estimate }\end{array}$ & $\begin{array}{l}\text { Standard } \\
\text { Error }\end{array}$ & \\
\hline$\gamma$ & 0.0082 & 0.0008 & close to log utility \\
\hline$\beta$ & 0.7490 & 0.0367 & discount rate $34 \%$ \\
\hline$\lambda$ & 0.1969 & 0.0064 & conversion parameter \\
\hline$\delta$ & 0.1330 & 0.0070 & depreciation rate \\
\hline$\pi$ & 0.0330 & 0.0039 & rain elasticity \\
\hline$\sigma_{1}$ & 0.2691 & 0.0555 & standard error of $\varepsilon_{1}$ \\
\hline$\sigma_{2}$ & 0.2768 & 0.0350 & standard error of $\varepsilon_{2}$ \\
\hline$\rho_{12}$ & 0.8649 & 0.0170 & correlation of $\varepsilon_{1}, \varepsilon_{2}$ \\
\hline$\tau$ & 0.0089 & 0.0220 & rate of technical progress \\
\hline
\end{tabular}

Table 2: Other Model Parameters

The estimated value of $\gamma$ is very close to zero, implying log utility and a unitary degree of relative risk aversion. The estimate of $\beta$ suggests a high degree of impatience: a discount rate of $34 \%$. The depreciation rate $\delta$ should be interpreted as a net rate, reflecting not just the aging and death of animals but also livestock births. The (co)variance parameters of the idiosyncratic shocks are highly significant. The estimates imply that the standard deviation of $\ln s_{1}$ is equal to 0.27 and that of $\ln s_{2}$ 0.28. The correlation between the two types of shocks is 0.86 . These estimates imply a very high level of idiosyncratic risk. For example, the probability that in any year a household experiences a shock of at least $10 \%$ of its income $\left(s_{1}>1.1\right.$ or $\left.s_{1}<0.9\right)$ is $71 \%$. The rate of technical progress is only imprecisely estimated. An earlier estimate using a different methodology (Gunning et al., 2000) was higher, but within the 95\%-confidence interval around our point estimate of slightly below $1 \%$ per year. The estimated value of $\pi$ is very significant but remarkably low. ${ }^{26}$

In our model every household is essentially a single-agent economy. In particular, households do not pool idiosyncratic risk. This is clearly a very strong assumption. It might seem that this assumption necessarily biases the results in the direction of an overstatement of the effect of growth on risk. This is not the case. Consider a proportional risk pooling arrangement which provides partial insurance, presenting an agent with a shock $\xi s(0<\xi<1)$

\footnotetext{
${ }^{26}$ This is a common empirical finding; cf. Rosenzweig and Binswanger (1993, p. 64).
} 
when a shock $s$ occurs. By ignoring the existence of such an arrangement our estimation procedure will understate the extent of risk: it will in fact produce an estimate of $\sigma \xi$ rather than of $\sigma$ : the partial insurance institution is observationally equivalent to a reduction in risk. In this case our estimate of the effect of risk on growth would be unaffected. ${ }^{27}$

\section{Results}

We use the estimated model to estimate the effect of risk on growth. Simulation results for a particular household are shown in Figure 1. Four paths of the real value of the capital stock (scaled by the household's labour force) are graphed over a 50-year period, starting at $t=0$ from the household's actual starting position. ${ }^{28}$.

The "sample path" is one possible growth path, defined by a particular series of 50 randomly drawn shocks, one for each year. The point to note is how very volatile this path is: the capital stock (livestock) frequently changes by as much as 50\% up or down in the course of one or two years. ${ }^{29}$ Clearly, the econometrician who had time-series data for part of this growth path would find it very difficult to say something about the underlying growth process.

\footnotetext{
${ }^{27}$ We can go slightly further by testing for partial insurance whereby shock $s$ is replaced by insurancemodified shock $A+B s$, where $-A$ can be interpreted as the 'insurance premium' and $B$ as the degree of risk mitigation. Note that with log-normally distributed shocks $s$ and $A, B \neq 0, A+B s$ is not log-normally distributed so that the model would be misspecified for this type of risk pooling. If risk sharing is important, we would therefore expect a significantly improved fit by allowing $A$ and $B$ to vary. The signs of $A$ and $B-1$ would depend on whether the sample households' average position is 'long' or 'short'. The unrestricted estimation results give a value of $A$ which is not significantly different from zero and a value of $B$ which is not significantly different from 1 . Also, the likelihood shows very little improvement as a result of dropping the restrictions $A=0, B=1$. We conclude that in this sample the weak test of "no risk pooling" is passed. This may reflect the particular nature of the sample: the resettlement farmers came from different parts of the country and therefore had no previous ties.

${ }^{28}$ This household has values of total factor productivity and initial capital close to the median in the sample. If we calculate means over households a very similar Figure results. We scale by dividing the capital stock by the labour force times the factor $(1+\tau)^{T}$ so that (in these units) the capital stock converges to a constant level in the deterministic case.

${ }^{29}$ These simulation results are confirmed by the data which show large shocks in the $k$ time series. A simple regression of $\ln k$ on its lagged value gives a residual standard error of 0.3 . This implies that changes of $50 \%$ are indeed quite common.
} 


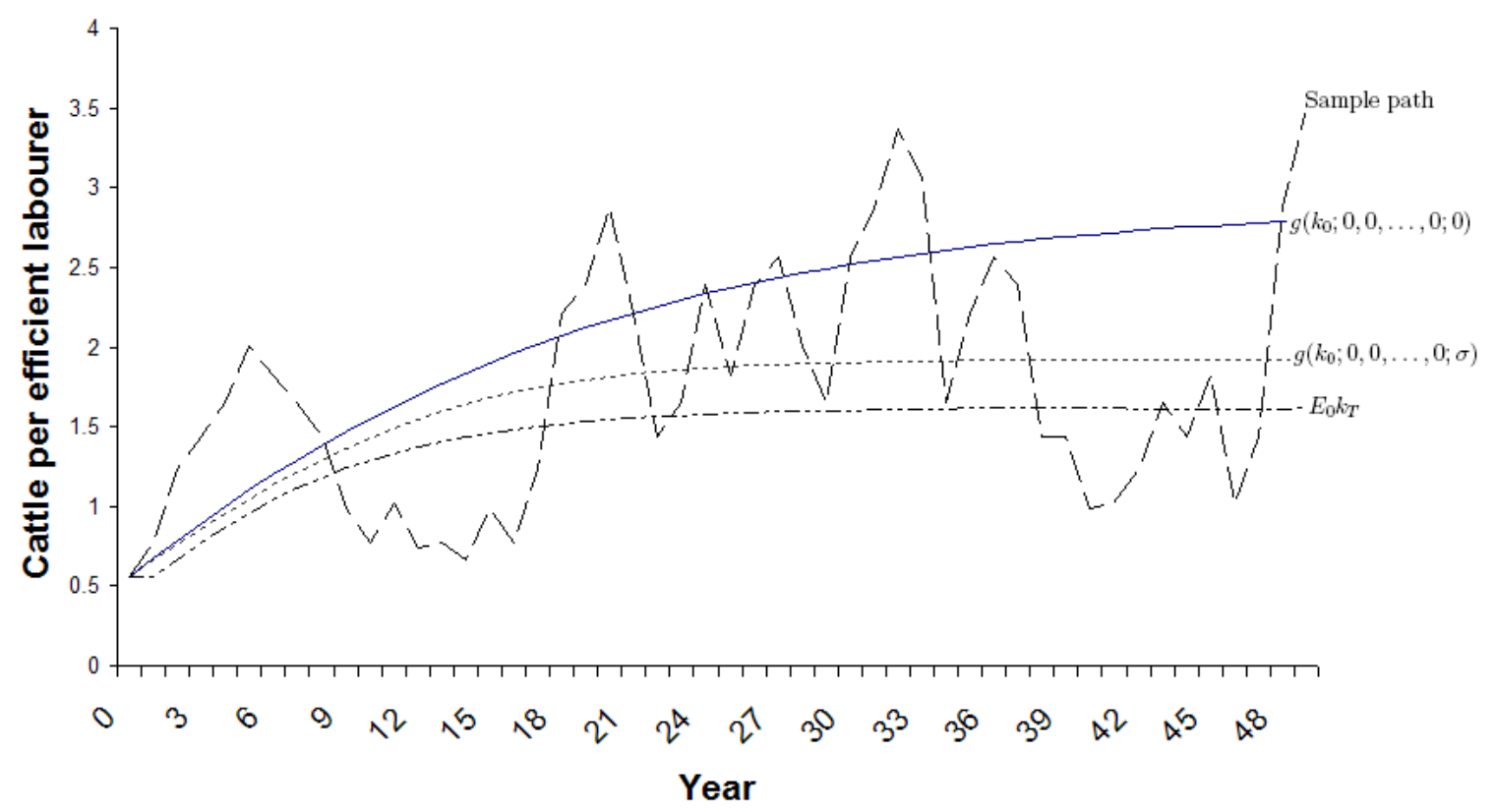

Figure 1: Growth and Risk: Capital Accumulation for a Selected Household. 
A large number $(100,000)$ of such growth paths were generated. For each year the expected value of the household's capital stock was then calculated as the mean over these paths. The time path of this mean is shown in the Figure as $E_{0} k_{T}$ (for $T=1, . ., 50$ ). The averaging procedure, of course, removes the volatility. The path shows how much livestock the household would expect to attain at future dates, from the standpoint of $t=0$. Since the household starts out very poor (with $k_{0}=0.56$ ) it grows initially very rapidly (in expectation), at some $9 \%$ per year in the first ten years.

Now consider the effect of risk on growth. Initially we keep the distribution of shocks unchanged but instead of drawing shocks $s$ from this distribution we present the household with $s=E s=1$ in each period. Hence the household faces the same risk as before but, as it happens, never experiences a shock. In the Figure we show this as the $g\left(k_{0} ; 1, . .1 ; \sigma\right)$ path, using the notation of section 2. The vertical difference between this curve and path $E_{0} k_{T}$ represents the ex post effect. Next we calculate the path of $k$ in the absence of risk. We do this by taking the (co)variances of the shocks to 0 while, as before, presenting the household with $s=E s=1$ in each period. Clearly, this implies that the household solves a non-stochastic optimisation problem: it knows that it faces no risk and indeed experiences no shocks at any point in time. This gives us the path of $g\left(k_{0} ; 1, . .1 ; 0\right)$, shown as the solid curve in the Figure. By construction the vertical distance between this curve and the path $g\left(k_{0} ; 1, . .1 ; \sigma\right)$ measures the ex ante effect.

Note that the effect of risk is massive: the household would have accumulated much more capital in the absence of risk. For this household the total effect of risk is dominated by the ex ante effect.

These results also apply to the sample households as a group. In the sample risk reduces the expected long run value of the capital stock, $E_{0} k_{50}, 46 \%$ below the steady state value $\left(k^{*}\right)$ in the deterministic (no risk) case: $E_{0} k_{50}=0.54 k^{*}$. This is a striking result. Risk does not only make growth very volatile (illustrated vividly by the "sample path") but it very 
much lowers growth on average. Of this reduction two-thirds is accounted for by the ex ante effect, the rest by the ex post effect. This also is a remarkable result. In much of the empirical literature (e.g. Ravallion, 1988, Dercon and Krishnan, 2000, Dercon, 2004) it is implicitly assumed that the actual shocks are an adequate measure of the effect of risk. This is not the case for the Zimbabwe households: much of the expected impact is internalised in the form of different investment decisions. Chronic poverty is often diagnosed as the result of poor endowments, as opposed to transient poverty which is seen as the result of risk. Our calculations show that risk has a very substantial effect on mean consumption as well. In that sense risk is a structural determinant of chronic poverty.

The no-risk case can be interpreted as what would happen if actuarially fair insurance were introduced. The sum of the ex ante and ex post effects then measures the effect of such insurance on capital accumulation. The Figure would look very similar if we had plotted welfare rather than capital accumulation; in particular the ranking of the three cases is the same: risk causes a substantial welfare loss and much of this loss is represented by the ex ante effect. The implication is that policies designed to reduce the exposure of households to risk or help households to cope with risk are welfare improving. In particular these households would gain substantially from the introduction of actuarally fair insurance.

\section{Conclusion}

Empirical work using micro data sets for rural households has uncovered much evidence of the impact of risk on income levels, investment and portfolio decisions, e.g. crop diversification. While the effect of risk on growth is recognised as a key issue in development, micro studies have seldom quantified it. This quantification is the central objective of the paper.

The paper makes three contributions. First, we have proposed a framework for analysing the effect of risk on growth, distinguishing between the ex ante and ex post effects of shocks. 
Secondly, we have estimated a stochastic growth model in its structural form, using simulation methods. If all households face the same risks (as we assumed in this paper) then the effect of risk on growth cannot be identified from a reduced form regression. Moreover, the use of simulation methods in estimating growth models removes the need for the simplifications (e.g. linearization around the steady state) usually adopted in applied work to make the estimation problem tractable.

Thirdly, turning from the methodology to the micro evidence, our application shows that for a sample of rural households in Zimbabwe (observed for almost a generation) risk has a very substantial effect on capital accumulation (and hence on poverty). We estimate that the average (across households) expected long-run capital stock is $46 \%$ lower than it would be in the absence of risk. This confirms the suggestion in the literature that self-insurance and other microeconomic responses to risk may substantially reduce growth.

The magnitude of the impact of risk on economic growth in Zimbabwe suggests that policy makers may need to reconsider the balance between interventions which address "structural" determinants of poverty (e.g. raising productivity through education or improvements in farm practices) and interventions which reduce exposure to shocks or help households in risk management. Our results suggest that the welfare costs of risk can be very high. The potential benefits of policy interventions to reduce exposure to risk or promote insurance or credit may therefore be much greater than previously envisaged. ${ }^{30}$ Such policies are usually seen as reducing the volatility of household income around a given mean. Our result that risk can massively reduce the "given" mean implies that this perspective (common in the literature on household vulnerability) can be misleading: much of what is classified as structural poverty may in fact reflect households' exposure to risk.

\footnotetext{
${ }^{30} \mathrm{~A}$ third possibility is to introduce a fixed return (safe) asset. The effect of this would be to increase total accumulation (in the two assets taken together) while reducing the accumulation of the risky asset. The reason is that the return on the safe asset establishes a floor under the expected marginal return of the risky asset. (This is similar to a deterministic model where the existence of the fixed return asset induces a switch from capital accumulation, subject to decreasing marginal productivity, to the fixed return asset.)
} 
We have stressed that the design of the land reform program makes the Zimbabwe case rather special, e.g. by severely limiting the scope for diversification and reducing the incentives for investment in education. Extending this work to other countries is therefore an important research area: to what extent the Zimbabwe results generalise is still very much an open question. Also, our model involves some stark simplifications. We intend to relax these in future work, notably by increasing the number of assets and allowing for informal risk pooling. 


\section{Appendix: Solving the Stochastic Ramsey Model}

Consider the case where there is no technical progress so that $\widetilde{a}$ is constant. Define wealth on hand $(w)$ as $w=s_{1} \tilde{a} f(k)+s_{2}(1-\delta) k$ and shocks as $s=\left(s_{1}, s_{2}\right)$. If a solution exists the model can be written in recursive form as the stationary Bellman equation:

$$
V(w(k, s))=\max _{\tilde{k}} u(w(k, s)-\tilde{k})+\beta E V(w(\tilde{k}, \tilde{s}))
$$

with associated policy function

$$
\varphi(w(k, s))=\arg \max _{\tilde{k}} u(w(k, s)-\tilde{k})+\beta E V(w(\tilde{k}, \tilde{s}))
$$

where $k$ and $\tilde{k}$ denote the capital stock at the beginning and the end of the current period and $s$ and $\tilde{s}$ denote current and future shocks. Equation (7) applies to every period so that time subscripts can be suppressed. Note that the policy function $\varphi$ maps the current $(k, s)$

into $\tilde{k}$, next period's $k$. Hence $\varphi$ can be seen as an investment function, giving $k_{t+1}$ as a function of wealth on hand $w_{t}$ (itself a function of the capital stock $k_{t}$ and the current shocks $\left.s_{t}\right)$.

A finite value function $V$ which satisfies the Bellman equation $(7)$ for all $(k, s)$ is a solution to the original maximization problem (3). $V$ and $\varphi$ satisfy the first order condition:

$$
u^{\prime}(w(k, s)-\varphi(w(k, s)))=\beta E V^{\prime}(w(\tilde{k}, \tilde{s})) \frac{\partial w(\tilde{k}, \tilde{s})}{\partial \tilde{k}}
$$

and the envelope condition

$$
V^{\prime}(w)=u^{\prime}(w-\varphi(w))
$$

The first condition equates the current marginal utility of consumption to the expected discounted value of a future extra unit of wealth on hand. The second condition states that 
the marginal value of wealth on hand $(w)$ is equal to the marginal utility of the corresponding consumption $(w-\varphi(w))$.

It is typically not possible to solve the two conditions analytically. We use an approximation by restricting and rounding variables to a fine but finite grid of $(w, k, s)$ values. The key to the solution of the resulting discrete system is the observation that the program value $V(\cdot)$ and the policy function $\varphi(\cdot)$ are functions of a single variable $w$. With only finite sets of values for $(k, s)$ and $\tilde{w}$ rounded to the nearest grid value for wealth on hand, it is easy to calculate the probabilities $p_{i j}=\operatorname{Prob}\left[w\left(k_{i}, s\right)=w_{j}\right]$ so that the equation to solve becomes

$$
V\left(w_{\ell}\right)=\max _{i} u\left(w_{\ell}-k_{i}\right)+\beta \sum_{j} p_{i j} V\left(w_{j}\right), \text { for all } \ell .
$$

This equation can be solved by iteration, with arbitrary initial values for $V\left(w_{\ell}\right), \ell=1,2, \ldots$. Since $\beta<1$ the iteration converges. ${ }^{31}$ Given the solution $V\left(w_{\ell}\right)$ it is straightforward to derive the corresponding policy function $\varphi\left(w_{\ell}\right)$. The extension to the case with technical progress $(\tau>0)$ is straightforward.

It should be noted that this policy function is a proximate solution to the stochastic Ramsey problem. The approximation involves discretisation and the imposition of a finite end time. Obviously this may affect the solution. Currently the authors are experimenting with alternative solution methods which (unlike the method described here) yield a policy function which is continuous in wealth on hand.

\footnotetext{
${ }^{31}$ See Stokey and Lucas (1989, pp. 82-83).
} 


\section{References}

Alderman, Harold, John Hoddinott and Bill Kinsey (2004), 'Long Term Consequences of Early Childhood Malnutrition', IFPRI Working Paper.

Barro, Robert J. and Xavier Sala-i-Martin (1995), Economic Growth, New York: McGrawHill.

Bliss, Christopher (1999), 'Galton's Fallacy and Economic Convergence', Oxford Economic Papers, vol. 51, pp. 4-14.

Carroll, Christopher (2001), 'Death to the Log-Linearized Consumer Euler Equation! (And Very Poor Health to the Second-Order Approximation.)', Advances in Macroeconomics, vol. 1 , article 6 .

Collier, Paul and Jan Willem Gunning (1999), 'Explaining African Economic Performance', Journal of Economic Literature, vol. 36, pp. 64-111.

Collier, Paul and Jan Willem Gunning (1999a), Trade Shocks in Developing Countries, Oxford: Oxford University Press.

Deaton, Angus (1991), 'Saving and Liquidity Constraints', Econometrica, vol. 59, pp. 12211248.

Deaton, Angus (1992), Understanding Consumption, Oxford: Clarendon Press.

Dehn, Jan (2000), 'Commodity Price Uncertainty and Shocks: Implications for Investment and Growth', D.Phil. thesis, University of Oxford.

de Hek, Paul (1999), 'On Endogenous Growth under Uncertainty', International Economic Review, vol. 40, pp. 727-744.

Dercon, Stefan (1996), 'Risk, Crop Choice and Savings: Evidence from Tanzania', Economic Development and Cultural Change, vol. 44, pp. 485-514.

Dercon, Stefan and Pramila Krishnan (2000), 'Vulnerability, Seasonality and Poverty in Ethiopia', Journal of Development Studies, vol. pp. 25-53.

Dercon, Stefan (2003), 'The Microeconomics of Poverty and Inequality', in Proceedings of the AFD-EUDN Conference 2003, Paris: Agence francaise de développement, pp. 135167.

Dercon, Stefan (2004), 'Growth and Shocks: Evidence from Rural Ethiopia', Journal of Development Economics, vol. 74, pp. 309-329.

Dercon, Stefan (2005), 'Risk, Insurance and Poverty: a Review'. In Stefan Dercon, ed., Insurance against Poverty, Oxford: Oxford University Press for WIDER. 
Easterly, William, Michael Kremer, Lant Pritchett and Lawrence H. Summers (1993), 'Good Policy or Good Luck? Country Growth Performance and Temporary Shocks', Journal of Monetary Economics, vol. 32, pp. 459-483.

Elbers, Chris and Jan Willem Gunning (2003), 'Estimating the Stochastic Ramsey Model from Household Panel Data', mimeo, Department of Economics, Free University, Amsterdam.

Epstein, Larry G. and Stanley E. Zin (1991), 'Substitution, Risk Aversion, and the Temporal Behavior of Consumption and Asset Returns: an Empirical Analysis', Journal of Political Economy, vol. 99, pp. 263-286.

Gouriéroux, Christian and Alain Monfort (1996), Simulation-based Econometric Methods, New York: Oxford University Press.

Guillaumont, Patrick and Lisa Chauvet (2001), 'Aid and Performance: a Reassement', Journal of Development Studies, vol. 37, pp. 66-92.

Gunning, Jan Willem, John Hoddinott, Bill Kinsey and Trudy Owens (2000), 'Revisiting Forever Gained: Income Dynamics in the Resettlement Areas of Zimbabwe', Journal of Development Studies, vol. 36, pp. 131-154.

Hoogeveen, Hans (2001), 'Risk and Insurance in Rural Zimbabwe', Ph.D. thesis, Free University, Amsterdam; Tinbergen Institute Research Series no. 247.

Jalan, Jyotsna and Martin Ravallion (2001), 'Behavioral Responses to Risk in Rural China', Journal of Development Economics, vol. 66, pp. 23-49.

Jalan, Jyotsna and Martin Ravallion (2005), 'Household Income Dynamics in Rural China', in Stefan Dercon (ed.),] Insurance against Poverty, Oxford: Oxford University Press.

Levhari, David and T.N. Srinivasan (1969), 'Optimal Savings under Uncertainty', Review of Economic Studies, vol. 36, pp. 153-163.

Lucas, Robert E., Jr. (1987), Models of the Business Cycle, New York: Basil Blackwell.

Lucas, Robert E., Jr. (2003), 'Macroeconomic Priorities', American Economic Review, vol. 93, pp. 1-14.

Morduch, Jonathan (1999), 'Between the State and the Market: Can Informal Insurance Patch the Safety Net?', World Bank Research Observer, vol. 14.

Murphy, Kevin M. and Robert H. Topel (1985), 'Estimation and Inference in Two-Step Econometric Models', Journal of Business and Economic Statistics, vol. 3, pp. 370-379.

Newbery, David M.G. and Joseph E. Stiglitz (1981), The Theory of Commodity Price Stabilization, Oxford: Clarendon Press. 
Ramey, Garey and Valerie A. Ramey (1995), 'Cross-Country Evidence on the Link Between Volatility and Growth', American Economic Review, vol. 85, pp. 1138-1151.

Ravallion, Martin (1988), 'Expected Poverty under Risk-Induced Welfare Variability', Economic Journal, vol. 98, pp. 1171-1182.

Rosenzweig, Mark R. and Hans Binswanger (1993), 'Wealth, Weather Risk and the Composition and Profitability of Agricultural Investments', Economic Journal, vol. 103, pp. 56-78.

Rosenzweig, Mark R. and Kenneth Wolpin (1993), 'Credit Market Constraints, Consumption Smoothing, and the Accumulation of Durable Production Assets in Low-Income Countries: Investment in Bullocks in India', Journal of Political Economy, vol. 101, pp. 223-244.

Stokey, Nancy L. and Robert E. Lucas Jr. (1989), Recursive Methods in Economic Dynamics, Cambridge, Mass.: Harvard University Press. 